\title{
A didática da história de J. G. Droysen: constituição e atualidade
}

\author{
Arthur Alfaix Assis[1]
}

\section{Resumo}

A teoria da história desenvolvida por Johann Gustav Droysen (1808-1884) distingue-se, entre outros aspectos, pela sua consistente preocupação com temas didáticos. Além de investigar os princípios que regem o método de trabalho dos historiadores e de perscrutar os motivos que nos levam a considerar como "históricas" certas porções do passado, ela também fornece respostas à pergunta "por que escrever, estudar e aprender história?”. Em linhas gerais, Droysen propõe que a finalidade do estudo da história não deve ser nem a assimilação de exemplos práticos, nem a memorização de fatos particulares, mas o aprendizado do que designou "pensamento histórico". Com esse argumento, Droysen contribuiu, penso eu, para uma redefinição importante da função didática da historiografia. O presente texto caracteriza e contextualiza tal redefinição, discutindo também seus potenciais e limites.

Palavras-chave: teoria da história; ensino de história; historiografia alemã - século XIX.

\section{J. G. Droysen's didactics of history: constitution and currentness}

\section{Abstract}

The historical theory developed by Johann Gustav Droysen (1808-1884) stands out partly due to its consistent orientation towards didactical issues. Besides investigating the principles governing the historical method and the reasons that lead us to attribute the quality of being "historical" to certain portions of the past, it also devised answers to the question: "why should one write, study, and learn history?". In short, Droysen argues that the main goal of studying history should be neither the assimilation of practical examples nor the memorization of particular facts, but rather the learning of what he called "historical thinking." I believe that Droysen's argument set in motion a very significant redefinition of historiography's didactical function. This article characterizes and contextualizes such redefinition, underlining some of its current potentials and limits.

Keywords: philosophy of history; historical education; German historiography $-19^{\text {th }}$ Century.

\section{La didáctica de la historia de J. G. Droysen: constitución y actualidad}

\section{Resumen}

La teoría histórica desarrollada por Johann Gustav Droysen (1808-1884) se distingue, entre otras cosas, por su preocupación constante con temas didácticos. Además de investigar los principios que rigen el método de trabajo de los historiadores y examinar las razones que nos llevan a considerar como "históricos" ciertos pasados, ella también ofrece respuestas a la pregunta “¿por qué escribir, estudiar y aprender la historia?". En resumen, Droysen sostiene que el objetivo principal del estudio de la historia no debe ser ni la asimilación de ejemplos prácticos ni la memorización de hechos particulares, sino el aprendizaje de lo que él llama "pensamiento histórico". Con este argumento, Droysen contribuyó, creo, a una redefinición importante de la función didáctica de la escritura de la historia. Este trabajo caracteriza y contextualiza tal redefinición, discutiendo también su actualidad y límites.

Palabras clave: teoría de la historia; enseñanza de la historia; historiografía alemana - siglo XIX.

\section{La didactique de l'histoire de J. G. Droysen: constitution et actualité}

\section{Résumé}

La théorie de l'histoire développée par Johann Gustav Droysen (1808-1884) se distingue par sa inquiétude quant aux thèmes didactiques. En plus d'investiguer les principes régissant la méthode de travail des historiens et d'étudier les raisons qui nous fait considérer certaines parties du passé comme «historiques», elle fournit des réponses à la question «Pourquoi écrire, étudier et aprendre l'histoire?». Généralement, Droysen propose que létude de l'histoire ne doit être par assimilation des exemples pratiques ni par mémorisation de certains événements, mais plutôt par l'apprentissage de ce qui a désignéla «pensée historique». Sur la base de cet argument, Droysen a contribué à la redéfinition de la fonction didactique de l'historiographie. Le présent texte caractérise et replace cette redéfinition et indique ses éventuelles limites.

Mots clés: théorie de l'histoire; enseignement de l'histoire; historiographie allemande, XIXe siècle.

Artigo recebido em 12 de Setembro de 2013 e aprovado para publicação em 30 de Outubro de 2013.

[1] Departamento de História da Universidade de Brasília (UnB) - Brasília (DF) - Brasil. E-mail: arthurassis@unb.br

Quase a totalidade das ideias que constam deste texto foram apresentadas e discutidas em mesa redonda do 70 Seminário Brasileiro de História da Historiografia, em Mariana, Minas Gerais, em 15 de agosto de 2013; em palestra ao Grupo de Pesquisa Espaços, Poder e Práticas Sociais, da Universidade Federal do Rio Grande do Norte, em 12 de dezembro de 2012; e em palestra ao Grupo de Pesquisa em Lógica e Filosofia da Ciência, da Universidade de Brasília, em 3 de dezembro de 2010. Aos organizadores e participantes dessas atividades, presto aqui os meus agradecimentos. Também agradeço a Itamar Freitas de Oliveira e aos dois pareceristas anônimos da Tempo pelas atentas leituras do manuscrito e pelas muitas e valiosas sugestões de melhoramento do texto. 


\section{O momento didático na obra de Droysen}

$\mathrm{E}$ m 1840, a trajetória acadêmica de Droysen passou por uma reviravolta na sequência da sua contratação como professor efetivo da Universidade de Kiel. Ele já tinha então concluído os seus estudos em Berlim, traduzido e comentado dramas de Ésquilo e Aristófanes e escrito uma importante biografia de Alexandre, o Grande - a que se seguiram os dois volumes de uma História do Helenismo. Com a mudança para o Norte, entretanto, ele relega ao segundo plano o interesse pelo mundo antigo e passa a dedicar a maior parte das suas atenções investigativas a períodos muito mais recentes do passado.

O principal motivo dessa mudança foi de natureza política. Droysen nascera cerca de dois anos depois do fim do Sacro Império Romano-Germânico e a maior parte da sua vida transcorreu num momento em que, no espaço cultural alemão, inexistia uma unidade política realmente forte. O tipo de historiografia que ele passou a cultivar desde mais ou menos 1845 espelhava o desejo de contribuir, pela via da interpretação histórica, com um projeto de construção do estado nacional alemão. É nesse espírito que se podem entender as suas duas grandes obras de história do que era então o tempo presente, a saber, as Conferências sobre as guerras da liberdade (1846) e a Biografia do Conde Yorck von Wartenburg (1851-1852) - um herói prussiano da guerra de resistência contra a dominação napoleônica. O mesmo se pode dizer daquela obra que o próprio Droysen considerava ser o seu trabalho mais importante, a História da política prussiana, cujos 14 volumes foram publicados entre 1855 e $1886 .^{2}$

É interessante conjecturar sobre qual seria, para nós, a atualidade e a relevância da obra de Droysen se ele tivesse se dedicado apenas à história prussiana. Neste caso, é plausível pensar que teríamos acerca dele uma percepção não muito distante da que hoje temos de um Heinrich von Treitschke, historiador que é associado antes a uma ideologia política no mínimo complicada que a uma prática de pesquisa digna de elogio. ${ }^{3}$

Isso, todavia, não se passa com Droysen, basicamente por duas razões. A primeira prende-se ao fato de Droysen ter, nas suas obras de juventude, conferido ao conceito de

\footnotetext{
20 melhor estudo crítico da trajetória pessoal e acadêmica de Droysen - ainda que hipercrítico com relação à relevância da teoria da história deste - é a biografia escrita por Wilfried Nipel, Johann Gustav Droysen. Ein Leben zwischen Wissenschaft und Politik, München, C.H. Beck, 2008. Antes da publicação do texto de Nipel a obra de referência sobre o tema era a biografia (inconclusa) preparada pelo próprio filho de Droysen. Ver Gustav Droysen, Johann Gustav Droysen, 1. Teil: Bis zum Beginn der Frankfurter Tätigkeit, Leipzig, B.G. Teubner 1910. Para outros estudos biográficos importantes, ver: Otto Hintze, "Johann Gustav Droysen". In: _... Zur Theorie der Geschichte. Gesammelte Abhandlungen, Leipzig, Koehler \& Amelang, 1942, p. 150-213; Werner Obermann, Der Junge Johann Gustav Droysen: Ein Beitrag zur Entstehungsgeschichte des Historismus, Tese de doutorado, Universität Bonn, Bonn, 1977; Stephan Paetrow, Johann Gustav Droysen in Jena. Ein Beitrag zur Entstehungsgeschichte von Droysens 〈Historik〉 und 〈Geschichte der preußischen Politik〉, Saarbrücken, VDM 2008; Jörn Rüsen, “Johann Gustav Droysen”, In: Hans-Ulrich Wehler (org.), Deutsche Historiker, Göttingen, Vandenhoeck \& Ruprecht, 1973, p. 115-131. Para resumos biográficos em português, ver: Arthur Alfaix Assis, “Johann Gustav Droysen”, In: Estevão de Rezende Martins (org.), A história pensada. Teoria e método na historiografia européia do século XIX, São Paulo, Contexto, 2010, p. 31-36; Pedro Spinola Pereira Caldas “Johann Gustav Droysen (1808-1884)", In: Maurício Parada (org.), Os historiadores: clássicos da História. Vol. 2 de Tocqueville a Thompson, Rio de Janeiro, PUC-Rio; Petrópolis, Vozes, 2013, p. 36-55.

3Ver: Andreas Dorpalen, "Heinrich von Treitschke”, Journal of Contemporary History, vol. 7, n. 3-4, 1972, p. 21-35.
} 
"helenismo" o significado de um conceito de época que se preserva até hoje. ${ }^{4}$ Mas éa segunda razão a que mais nos interessa aqui:Droysen mantém-se relativamente atual, sobretudo por causa das reflexões sobre teoria e metodologia da história que ele sistematizou em cursos oferecidos nas Universidades de Jena e Berlim entre 1857 e 1883. Enfim, é por causa dos seus textos de teoria da história que Droysen éfrequentemente lembrado como um autor clássico, tanto por historiadores de mente filosófica quanto por filósofos de mente histórica. Hannah Arendt, por exemplo, afirmou que ele terá sido "talvez o mais denso dos historiadores do séc. XIX". Hans Georg Gadamer ressaltou a importância de Droysen na trajetória da moderna hermenêutica, qualificando-o como um "arguto metodólogo". Para o historiador Thomas Nipperdey, autor de uma das mais respeitadas histórias da Alemanha oitocentista, Droysen foi o "grande teórico do historicismo". $\mathrm{A}$ lista de elogios pode parar por aqui, pois o ponto que se pretende ilustrar está claro: segundo a percepção de diversos analistas importantes, na Alemanha do século XIX, Droysen foi um dos autores que melhor encaminhou as questões teóricas ligadas à história e à historiografia.

\section{Droysen mantém-se relativamente atual, sobretudo por causa das reflexões sobre teoria e metodologia da história que ele sistematizou em cursos oferecidos nas Universidades de Jena e Berlim entre 1857 e 1883}

A perspectiva principal que estrutura a teoria da história de Droysen faz eco ao seu propósito de explicar os princípios que regulam o trabalho dos historiadores profissionais. Droysen costumava abrir as suas conferências teóricas com a afirmação de que, na sua época, a despeito do frequente sucesso das pesquisas empreendidas pelos historiadores, as questões mais fundamentais atinentes ao conhecimento histórico tendiam a permanecer sem respostas claras. ${ }^{6}$ Ele optou por pensar, ensinar e escrever sobre temas teórico-metodológicos depois de ter diagnosticado a necessidade de esclarecer os historiadores quanto à natureza e à importância da disciplina histórica. Por essa razão, pode-se dizer que a teoria da história de Droysen é, antes de mais nada, uma teoria da ciência histórica (Geschichtswissenschaft).

Tal teoria parte de uma caracterização das especificidades do "método histórico", isto é, de uma demonstração de que os procedimentos de pesquisa

\footnotetext{
${ }^{4}$ Ver, por exemplo, Hans-Joachim Gehrke, Geschichte des Hellenismus, München, Oldenbourg, 2003, p. 1: "Quando falamos hoje de Helenismo como uma época histórica, colocamo-nos dentro de uma tradição iniciada por Johann Gustav Droysen" (tradução do autor); Arnaldo Momigliano, "J.G. Droysen between Greeks and Jews", History and Theory, vol. 9, n. 2, 1970, p. 139-153: "It was J. G. Droysen who introduced the word Hellenism to designate the civilization of the Greek-speaking world after Alexander" (p. 139-140). Antes de Droysen, o termo "helenismo" já era usual, mas o seu campo semântico era bem mais restrito. O termo era comumente utilizado como referência aos judeus do mundo antigo que falavam grego. Cf. Arnaldo Momigliano, "J.G. Droysen between Greeks and Jews", History and Theory, vol. 9, n. 2, 1970, p. 142.

${ }^{5}$ Hannah Arendt, Entre o passado e o futuro, São Paulo, Perspectiva, 2001, p. 110; Hans-Georg Gadamer, Verdade e método. Vol. 1: traços fundamentais de uma hermenêutica filosófica, Petrópolis, Vozes, 2008, p. 285; Thomas Nipperdey, Deutsche Geschichte 1800-1866. Bürgerwelt und starker Staat, München, C.H. Beck, 1998, p. 517. ${ }^{6}$ Johann Gustav Droysen, Historik. Vol. 1: Rekonstruktion der ersten vollständigen Fassung der Vorlesungen (1857); Grundriß der Historik in der ersten handschriftlichen (1857-1858) und in der letzten gedruckten Fassung (1882), editado por Peter Leyh, Stuttgart, Frommann-Holzboog, 1977, p. 3-4; 417.
} 
utilizados pelos historiadores obedecem a regras que são características da disciplina histórica. ${ }^{7}$ Droysen aceita, portanto, a existência de um pluralismo científico, elaborando, a partir daí, uma justificação para a autonomia da história enquanto um campo acadêmico situado entre a filosofia e as ciências naturais. A mais conhecida citação atribuída a Droysen é a de que a essência do método histórico é o ato de "compreender pesquisando" (forschendes Verstehen). ${ }^{8}$ Tal formulação reflete bem o seu argumento de que a história ocupa uma posição intermediária entre a filosofia e as ciências naturais. Contrariamente à filosofia (e também à teologia), a história seria, de um lado, uma ciência empírica. Por outro, porém, a história refere-se ao seu material empírico de uma maneira que difere fundamentalmente de outras ciências, pois os historiadores não lidam com fenômenos naturais recorrentes, mas com os produtos singulares do pensamento e da ação humanas. ${ }^{9}$

A teoria da história de Droysen vai, na verdade, além de uma metodologia hermenêutica capaz de demarcar a especificidade da história diante de outras formas de conhecimento. Está, como já bem demonstrou Michael MacLean, imbricada em fortes motivos éticos e políticos. ${ }^{10}$ Abrange, além disso, uma série de microteorias, que eu só poderia listar aqui sumariamente: uma teoria das etapas da pesquisa histórica, uma teoria da historicidade, uma tipologia da representação histórica, uma teoria social, uma ética histórica, uma teoria política, entre outras. ${ }^{11}$ Tudo isso é costurado por uma visão religiosa e algo necessitarista do processo histórico, em linha com o que Droysen uma vez sugeriu que "a mais elevada tarefa da ciência histórica é, sim, a teodicéia,"12 isto é, a justificação da existência do mal num mundo criado por um Deus todo-poderoso e de bondade infinita. ${ }^{13}$

Todavia, Droysen julgava que a ciência histórica se revestia, paralelamente, de uma utilidade algo mais prosaica. Seria útil não só à resolução de certas tensões inerentes à religiosidade cristã, mas também a outros planos da vida prática dos seres humanos. Por isso, não é exagero dizer que, para ele, a atividade dos historiadores se liga ao desempenho de uma boa variedade de funções de orientação cultural. Para Droysen, a historiografia não deve ser feita como um fim em si mesmo, como uma espécie de arte pela arte, movida pela pura

\footnotetext{
7 Frederick Beiser, The German historicist tradition, Oxford, Oxford University Press, 2011, p. 291; 298.

${ }^{8}$ Johann Gustav Droysen, Historik. Vol. 1: Rekonstruktion der ersten vollständigen Fassung der Vorlesungen (1857); Grundriß der Historik in der ersten handschriftlichen (1857-1858) und in der letzten gedruckten Fassung (1882), editado por Peter Leyh, Stuttgart, Frommann-Holzboog, 1977, p. 22.

9Para uma interpretação aprofundada da concepção hermenêutica de método histórico desenvolvida por Droysen, ver Herbert Schnädelbach, Geschichtsphilosophie nach Hegel. Die Probleme des Historismus, Freiburg, Karl Alber, 1974, p. 101-111.

${ }^{10}$ Michael MacLean, "Johann Gustav Droysen and the development of historical hermeneutics", History and Theory, vol. 21, n. 3, 1982, p. 347-365.

"Para uma visão panorâmica mais detalhada da teoria da história de Droysen, ver Arthur Alfaix Assis, What is history for?, New York, Berghahn Books, 2014, p. 190-210.

12Johann Gustav Droysen, Historik. Vol. 2: Texte im Umkreis der Historik (1826-1882), editado por Horst Walter Blanke, Stuttgart, Frommann-Holzboog, 2007, p. 228.

13Sobre a importância da religião na concepção de história de Droysen, ver: Wolfgang Hardtwig, "Geschichtsreligion - Wissenschaft als Arbeit - Objektivität. Der Historismus in neuer Sicht", Historische Zeitschrift, n. 252, 1991, p. 1-32; Dirk Fleischer, 'Geschichtserkenntnis als Goterkenntnis'. Das theologische Fundament der Geschichtstheorie Johann Gustav Droysens", In: Horst Walter Blanke (org.), Historie und Historik. 200 Jahre Johann Gustav Droysen, Köln, Böhlau, 2009, p. 73-89.
} 
vontade de compreender mais e melhor uma porção do passado. Deve, antes, consistir numa interpretação pragmática do presente, capaz de dotá-lo da autoconsciência necessária para garantir a continuidade da própria história enquanto processo objetivo de desenvolvimento da humanidade. ${ }^{14}$

Segundo Droysen, a participação ativa das pessoas na vida histórica, nas diferentes esferas do "mundo ético", depende da aquisição por elas de uma competência subjetiva específica que só a historiografia é capaz de fomentar. Trata-se da competência que lhes permite ter a consciência de que, na sua constituição atual, tal mundo e as suas "esferas" (família, povo, língua, direito, religião, economia, política, entre outras) "são como são, porque assim se tornaram" ${ }^{15}$ Através disso, o indivíduo ascende a uma visão desnaturalizada do processo histórico, em que este deixa de ser experimentado passivamente enquanto destino inexorável e passa a aparecer como um devir sobre o qual se pode tentar exercer algum tipo de influência ativa.

A consciência da historicidade do mundo atual é, pois, o que, de acordo com Droysen, confere a mais importante garantia à continuidade do processo histórico. Um dos mais nobres objetivos que ele associa à prática historiográfica é justamente o de promover a difusão e o aprimoramento de tal consciência. "A tarefa dos estudos históricos", afirma Droysen lapidarmente, é que se aprenda a pensar historicamente". ${ }^{16}$ Com essa definição, ele queria sensibilizar os historiadores para o fato de que conhecimento histórico pode produzir um impacto prático que transcende o puro e simples entendimento do passado. Queria, na verdade, fortalecer a possibilidade de que o conhecimento do passado estimulasse, nos leitores e estudantes, a aprendizagem de uma determinada competência reflexiva: a capacidade de relacionar passado e presente de maneira histórica, de enriquecer a experiência atual com o conhecimento da experiência pretérita. Em outras palavras: o grande aprendizado a ser extraído da história era, para Droysen, em primeiríssimo lugar, relativo a uma forma geral de pensamento ou consciência e não a conteúdos factuais específicos. Esse argumento sintetiza boa parte da sua visão geral da historiografia enquanto uma forma de conhecimento prático, ao mesmo tempo em que dá a perceber a centralidade da reflexão didática no corpo da sua teoria da história.

\section{Ascensão e queda da justificativa exemplar}

Ao longo da trajetória de longo prazo da historiografia, definições pragmáticas do valor da história, como a formulada por Droysen, foram muito mais frequentes do que definições autotélicas, isto é, do que aquelas que atribuem à

\footnotetext{
14Johann Gustav Droysen, Historik. Vol. 2: Texte im Umkreis der Historik (1826-1882), editado por Horst Walter Blanke, Stuttgart, Frommann-Holzboog, 2007, p. 377-379.

15/dem, Historik. Vorlesungen über Enzyklopädie und Methodologie der Geschichte, editado por Rudolf Hübner, München, Oldenbourg, 1971, p. 301.

${ }^{16 / d e m}$, Historik. Vol. 1: Rekonstruktion der ersten vollständigen Fassung der Vorlesungen (1857); Grundriß der Historik in der ersten handschriftlichen (1857-1858) und in der letzten gedruckten Fassung (1882), editado por Peter Leyh, Stuttgart, Frommann-Holzboog, 1977, p. 5.
} 
historiografia um fim em si mesmo. Existe, porém, bem mais do que uma única maneira de conferir à história importância prática. Por muito tempo, no pensamento histórico ocidental, a principal forma do pragmatismo historiográfico correspondeu a um conjunto de argumentos que, para usar a expressão de George Nadel, se pode chamar de "teoria exemplar da história". ${ }^{17}$ Droysen estabeleceria, mais tarde, a sua didática do pensamento histórico precisamente em oposição a essa didática exemplarista. Por isso, para melhor compreender a primeira, é fundamental lançar um olhar sobre a segunda.

Teoria exemplar corresponde, nesse contexto, ao argumento de que existe uma razão prática para a escrita e o estudo da história. Diz respeito, mais especificamente, à ideia de que os textos de história comunicam às pessoas de um dado presente modelos e antimodelos de ação cuja eficácia já foi posta à prova em situações pretéritas. Sendo assim, a relevância das histórias residiria na sua capacidade de proporcionar aprendizagem política e/ou moral, mediada por exemplos de feitos passados.

A justificação exemplar da historiografia não é uma especificidade da tradição ocidental. Na verdade, encontra-se presente em quase todas as grandes tradições historiográficas e há, nas respectivas bibliografias especializadas, centenas, senão milhares, de referências ao tema. ${ }^{18}$ Pensemos, por exemplo, em Ibn Khaldūn, o grande clássico da historiografia islâmica. O seu livro de história universal tinha o título geral de Kitab al-Ibar, que se pode traduzir por "Livro dos exemplos". Na introdução do texto, pode-se ler o seguinte:

A história familiariza-nos com as condições dos povos do passado tais como refletidas no seu próprio caráter, com as biografias dos profetas, com as dinastias e com as políticas dos governantes. Quem quer que queira pode, portanto, [à luz da história] chegar ao ponto de estar apto para imitar exemplos históricos em assuntos de natureza religiosa e mundana. ${ }^{19}$

A trajetória do ramo ocidental da teoria exemplar é multifacetada. Os seus primeiros registros encontram-se na obra de retóricos e historiadores da era helenística. ${ }^{20}$ Políbio é talvez o mais notável expoente dessa fase inicial, com a sua definição da história como meio de treinamento para a vida política. Do retórico romano Cícero provém, todavia, a expressão que melhor sintetiza o argumento exemplar: historia magistra vitae. Ao longo dos vários séculos que nos separam de ambos os autores, a teoria exemplar da história ganhou

\footnotetext{
${ }^{17}$ George H. Nadel, "Philosophy of history before historicism", History and Theory, vol. 3, n. 3, 1964, p. 291-315 (esp. p. 292).

18Ver, por exemplo, Ying-shih Yü, "Reflections on Chinese historical thinking", In: Jörn Rüsen (org.), Western historical thinking: an intercultural debate, New York, Berghahn Books, 2002, p. $152-172$ (esp. p. 158); David Schaberg, "Chinese history and philosophy", In: Andrew Feldherr; Grant Hardy (orgs.), The Oxford history of historical writing. Vol. 1: beginnings to AD 600, Oxford, Oxford University Press, 2011, p. 394-414; Romila Thapar, Ancient Indian social history. Some interpretations, New Delhi, Orient Blackswan, 2006, p. 253.

${ }^{19}$ Abū Zayd Ibn Khaldūn, The Muqaddimah. An introduction to history, vol. 1, Princeton, Princeton University Press, 1967, p. 15 (tradução do autor).

${ }^{20}$ Para François Hartog, as histórias escritas no período clássico, por Heródoto e Tucídides, por exemplo, não revelam a predominância de justificativas e usos exemplares. Ver François Hartog, Os antigos, o passado e o presente, Brasília, Editora da UnB, 2003, p. 53-70.
} 
os mais diferentes contornos e feições, combinando-se com a tradição estoica, sendo assimilada por diferentes variações da visão cristã de mundo e associando-se à moderna razão de estado. Inúmeros intelectuais antigos, medievais e modernos concordavam (ou teriam concordado) com o velho dito segundo o qual a história nada mais é senão uma forma de "filosofia que ensina através de exemplos". ${ }^{21}$ Ousando um pouco, pode-se dizer que, nos universos culturais da Antiguidade, da Idade Média e da alta Idade Moderna ocidentais, a despeito das enormes transformações que marcam as diferenças de um período a outro, existia um relativo consenso cultural acerca da utilidade exemplar da história para a vida e do valor pedagógico dos exemplos históricos. ${ }^{22}$

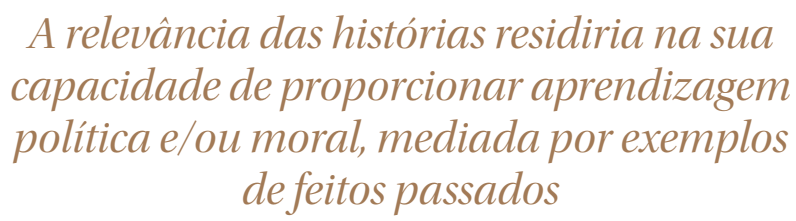

Ao padrão exemplar de justificação da historiografia corresponde uma didática da história, no sentido de uma concepção geral do que a historiografia pode ensinar e de como desta se pode aprender algo. A história da ascensão e queda de ambos, no que tange ao mundo ocidental, foi bem contada e documentada pelo próprio Nadel e, depois, por Reinhart Koselleck, sendo já razoavelmente conhecida. ${ }^{23}$ Com base na periodização pensada por esses e

\footnotetext{
${ }^{21}$ Essa passagem tem sido há muito tempo atribuída a Dionísio de Halicarnasso, importante historiador grego do século I a.C. O conjunto textual de que faz parte foi, muito provavelmente, escrito apenas no século II d.C. Ver Malcolm Heath, "Pseudo-Dionysius Art of Rhetoric 8-11: figured speech, declamation and criticism", American Journal of Philology, vol. 124, 2003, p. 81-105.

${ }^{22}$ Charles Fornara, The nature of history in ancient Greece and Rome, Berkeley, University of California Press, 1983, p. 104-120; Christian Meier, "Antiguidade", In: Reinhart Koselleck et al., O conceito de história, Belo Horizonte, Autêntica, 2013, p. 37-62 (esp. p. 49-50; 57); Gabrielle Spiegel, "Political utility in Medieval historiography: a sketch", History and Theory, vol. 14, n. 3, 1975, p. 314-325 (esp. p. 316-319); Odilo Engels, "Compreensão do conceito na Idade Média", In: Reinhart Koselleck et al., O conceito de história, Belo Horizonte, Autêntica, 2013, p. 63-84 (esp. p. 80); Rommily Jenkins, "The Hellenistic origins of Byzantine literature”, Dumbarton Oaks Papers, vol. 17, 1963, p. $37-52$ (esp. p. 50); Horst Günther, "Pensamento histórico no início da Idade Moderna", In: Reinhart Koselleck et al., O conceito de história, Belo Horizonte, Autêntica, 2013, p. 85-118 (esp. p. 90-93; 11-114); Felix Gilbert, Machiavelli and Guicciardini: politics and history in sixteenth century Florence, Princeton, Princeton University Press, 1973, p. 228; Anthony Grafton, What was history? The art of history in early modern Europe, Cambridge, Cambridge University Press, 2006, p. 31-32; Michel Jeanneret, "The vagaries of exemplarity: distortion or dismissal?", Journal of the History of Ideas, vol. 59, n. 4, 1998, p. 565-579 (esp. p. 578-579)

${ }^{23}$ George Nadel, "Philosophy of history before historicism", History and Theory, vol. 3, n. 3, 1964, p. 291 315; Reinhart Koselleck, Futuro passado: contribuição à semântica dos tempos históricos, Rio de Janeiro, Contraponto; Editora da PUC-Rio, 2006, p. 41-60. Sobre o tema, ver também: Arthur Alfaix Assis, "Por que se escrevia história? Sobre a justificação da historiografia no mundo ocidental pré-moderno", In: Marlon Salomon (org.), História, verdade e tempo, Chapecó, Argos, 2011, p. 105-132; Eckhard Keßler, "Geschichte: Menschliche Praxis oder kritische Wissenschaft? Zur Theorie der humanistischen Geschichtsschreibung", In: Eckhard Keßler (org.), Theoretiker humanistischer Geschichtsschreibung. Nachdruck exemplarischer Texte aus dem 16. Jahrhundert, München, Wilhelm Finck, 1971, p. 7-47; Hermann Lübbe, Geschichtsbegriff und Geschichtsinteresse: Analytik und Pragmatik der Historie, Basel, Schwabe, 1977, p. 204-224; Ulrich Muhlack, Geschichtswissenschaft im Humanismus und in der Aufklärung. Die Vorgeschichte des Historismus, München, C.H. Beck, 1991, p. 44-66; Jörn Rüsen, História viva. Teoria da história III: formas e funções do conhecimento histórico, Brasília, Editora da UnB, 2007, p. 50-55.
} 
outros autores, pode-se afirmar que a teoria exemplar da história se manteve enquanto forma preponderante de justificação da historiografia e da aprendizagem histórica pelo menos até a segunda metade do século XVIII.

Por ironia do destino, a mais elaborada das teorias exemplares foi preparada justamente nas últimas décadas de hegemonia dessa antiga maneira de definir o valor da historiografia. Encontra-se nas Cartas sobre o estudo e a utilidade da história, escritas por Bolingbroke em 1735. Esse filósofo de proveniência aristocrática trilhou uma trajetória meteórica no cenário político inglês de inícios do séculoXVIII, mas caiu em desgraça após a entronização de Jorge I. Mais de uma vez exilado, com os direitos políticos caçados, os títulos nobiliárquicos anulados e as propriedades sob ameaça, ele volta-se, no fim da vida, para os estudos filosóficos e históricos. ${ }^{24}$

As Cartas sobre o estudo e a utilidade constituem "um dos mais importantes textos sobre a ideia de história na Inglaterra". ${ }^{25}$ Dão testemunho de uma posição acerca da importância da historiografia que se coloca em franca oposição à noção, desenvolvida entre cronólogos, antiquários e demais usuários do método crítico, de que o conhecimento histórico teria um propósito em si mesmo. ${ }^{26}$ Bolingbroke despreza toda e qualquer pesquisa fatual que esteja desvinculada de propósitos práticos genuínos e faz uso de uma linguagem bastante expressiva para marcar a sua posição. Afirma preferir incidir em anacronismos a correr atrás da "tralha erudita que enche a cabeça de um antiquário". Equipara gramáticos e filólogos a "burros de carga" perdidos nos "labirintos da Antiguidade". Considera, enfim, que a erudição não passa de uma "forma inventiva e enganosa de indolência".27 Em linha com essas incisivas críticas à "erudição pela erudição", Bolingbroke argumenta fortemente pela conveniência de uma pedagogia histórica baseada em exemplos e contrariamente ao recurso a preceitos filosóficos de caráter teórico. “Tamanha é a imperfeição do entendimento humano [...]”, defende ele,

\begin{abstract}
que proposições gerais e abstratas, mesmo que verdadeiras, se nos parecem obscuras e duvidáveis, até que sejam explicadas por exemplos; e que as mais sábias lições de virtude dificilmente convencem o juízo e determinam a vontade, a não ser que sejam executadas através daqueles meios. ${ }^{28}$
\end{abstract}

Todavia, nas décadas seguintes, a combinação entre iluminismo e historicismo que fermentou o pensamento filosófico e histórico nos países de língua alemã daria ocasião ao surgimento de um novo conjunto de expectativas em relação à historiografia, à luz das quais o discurso exemplar acerca da aprendizagem histórica passa a parecer mais e mais obsoleto. Estou aludindo aqui ao processo de formação do moderno conceito de história, tal como analisado

\footnotetext{
${ }^{24}$ Isaac Kramnick, Bolingbroke and his circle: the politics of nostalgia in the age of Walpole, Ithaca, Cornell University Press, 1992, p. 8-16. Ver também: Philip Hicks, "Bolingbroke, Clarendon, and the Role of Classical Historian", Eighteenth-Century Studies, vol. 20, n. 4, 1987, p. 445-471.

${ }^{25}$ George Nadel, "New lights on Bolingbroke's letters on History", Journal of the History of Ideas, vol. 23, n. 4, 1962, p. 550-557 (esp. p. 557). (tradução do autor).

${ }^{26}$ Ulrich Muhlack, Geschichtswissenschaft im Humanismus und in der Aufklärung. Die Vorgeschichte des Historismus, München, C.H. Beck, 1991, p. 391.

${ }^{27}$ Bolingbroke (Henry St. John), Letters on the study and the use of history, London, T. Cadell, 1779, p. 9; 13-14.

${ }^{28}$ Odem, Ibidem, p. 15.
} 
por Koselleck. Nesse conceito, estaria simbolizada uma nova ordem temporal em que o tempo é experimentado como um amplo e progressivo continuum a ligar passado e futuro com a intermediação do presente.

Um dos mais fundamentais argumentos que subjazem à análise de Kosellecké o de que a emergência da noção de história como o macroprocesso de desenvolvimento da humanidade se deu em paralelo com o avanço da percepção da singularidade e da irrepetibilidade dos acontecimentos históricos. Com efeito, do final do século XVIII em diante, disseminou-se em parte do mundo ocidental a noção de que se vivia num tempo radicalmente novo. Isso impeliu diversos filósofos e historiadores, que atuavam, sobretudo, no espaço cultural alemão, a adotarem uma atitude inédita de temporalização diante do passado e do presente. Começou-se então a enfatizar a singularidade do presente e das épocas do passado; começouse, enfim, a historicizar propriamente o passado e o presente. Em virtude da crescente tendência para se temporalizar a relação com a experiência, o passado tornou-se cada vez menos diretamente relevante para o presente. ${ }^{29}$

Essa transformação do conceito de história, juntamente com as novas possibilidades de temporalização da experiência por ela incentivadas, também gerou consequências sobre a maneira de se definir o valor e a função da historiografia. Apresentando-se como o recurso fundamental para a apreensão cognitiva de uma experiência histórica única e irrepetível, a historiografia move-se então para longe da velha exemplaridade. ${ }^{30}$ De fato, vistos desde uma perspectiva lógica, os exemplos históricos apenas podem reivindicar validade geral no contexto de uma representação do tempo que neutraliza a diferença entre presente e passado. Historicamente, tal neutralização se deu amiúde por meio do recurso a um conceito supratemporal de natureza humana, isto é, por meio de uma representação fixa e invariável da essência do humano.

O fato é que a ênfase moderna nos processos, na unicidade dos acontecimentos e na historicidade da natureza humana fragilizou um dos pilares da teoria exemplar da história, a saber, a ideia de que os exemplos possuem uma validade trans-histórica, ou seja, de que valem para diferentes contextos temporais. Alguns autores de princípios do século XIX parecem ter tido clara consciência de tais mutações. Hegel, por exemplo, no começo da sua Filosofia da história, afirma peremptoriamente:

o que a experiência e a história ensinam é que os povos e os governos jamais aprenderam coisa alguma da história e não seguiram o ensinamento que ela poderia ter inspirado. Cada época se encontra em circunstâncias tão peculiares, representa uma situação tão individual que as decisões sobre como agir só podem ser tomadas por referência a ela própria. ${ }^{31}$

\footnotetext{
${ }^{29}$ Reinhart Koselleck, "'História' como conceito mestre moderno", In: Reinhart Koselleck et al., O conceito de história, Belo Horizonte, Autêntica, 2013, p. 185-222 (esp. p. 202-203); Koselleck, Futuro passado: contribuição à semântica dos tempos históricos, Rio de Janeiro, Contraponto; Editora da PUC-Rio, 2006, p. 55-56.

30/dem, "A configuração do moderno conceito de história", In: Reinhart Koselleck et al., O conceito de história, Belo Horizonte, Autêntica, 2013, p. 119-184 (esp. p. 160-164).

${ }^{31}$ Georg Wilhelm Friedrich Hegel, Filosofia da história, Brasília, Editora da UnB, 1999, p. 15 (tradução ligeiramente modificada).
} 
O ponto mesmo reaparece no pensamento de um dos mais polivalentes intelectuais da era de ouro do idealismo alemão, Wilhelm von Humboldt. Segundo ele, "[a história não presta serviço à vida] ao fornecer exemplos que devem ser seguidos ou evitados, pois isto geralmente conduz ao erro e raramente ensina". ${ }^{2}$

\section{A ressignificação da história enquanto conhecimento prático}

Não obstante essas e outras críticas, muito poucos foram os intelectuais que, nos séculos XVIII e XIX, trabalharam numa resposta consistente à questão: para que serve a história quando se a retira do pedestal de mestra da vida? Essa é uma das circunstâncias que conferem uma importância especial à teoria da história de Droysen.

Droysen foi um dos primeiros intelectuais a extrair todas as consequências da moderna crítica à justificação exemplar da historiografia. Reconhecendo a inadequação dos exemplos históricos, ele começa a reajustar o foco e as metas da aprendizagem histórica. Para ele, produtores e receptores do conhecimento histórico deviam concentrar-se não na transmissão e no aprendizado de máximas concretas de conduta prática, mas, sim, no desenvolvimento de certas habilidades de pensamento. "Pensamento histórico" torna-se, assim, a

Hegel, no começo da sua Filosofia da história,
afirma peremptoriamente: "o que a experiência
e a história ensinam é que os povos e os governos
jamais aprenderam coisa alguma da história"

etiqueta de uma significativa mudança de paradigma.

A definição de Droysen assenta-se, como acabei de indicar, sobre uma rejeição decidida dos princípios que fornecem sustentação à exemplaridade histórica. Mas seria um grande equívoco enxergar nessa atitude antiexemplar sinais de repúdio geral a uma visão pragmática de historiografia. Na verdade, Droysen pretendia reconstruir, em terreno novo, os velhos laços pragmáticos entre história e vida, anteriormente conservados na máxima ciceroniana. Por isso, pode-se dizer que, na sua noção de pensamento histórico, estava embutida uma tentativa relativamente moderada de substituir a teoria exemplar da história.

Quando falava em "pensamento histórico", Droysen dava destaque à sua percepção de que história se faz sempre na conexão entre passado e presente (e futuro, naturalmente). Uma maneira de traduzir esse seu insight é com um

${ }^{32}$ Wilhelm von Humboldt, "Sobre a tarefa do historiador", In: Estevão de Rezende Martins (org.), A história pensada. Teoria e método na historiografia europeia do século XIX, São Paulo, Contexto, 2010, p. 82-100 (esp. p. 86). 
truísmo: pensar historicamente é o mesmo que ser capaz de colocar passado e presente em perspectiva histórica. A capacidade de pensar historicamente confunde-se, assim, com a habilidade para historicizar o passado e o presente. Para Droysen, a historicização do passado implica necessariamente uma perspectivação histórica do sujeito do pensamento histórico no presente. Droysen exprime aqui o núcleo duro da teoria historicista do conhecimento, nos quadros da qual o passado objetivo tornado conhecido pelos historiadores repercute dentro do próprio sujeito do conhecimento e dos seus destinatários. ${ }^{33}$ Conhecer o passado com a ajuda das ciências históricas é, assim, uma forma de autoconhecimento.

Uma importante costura dessa teoria historicista do conhecimento é executada pelo conceito idealista e neo-humanista de Bildung. "Que se aprenda a pensar historicamente" é uma fórmula associada a uma pretensão formativa - no sentido alemão do termo "formação". Relaciona-se diretamente com um projeto de desparticularização e universalização das formas de orientação cultural da vida. Para o professor filosófico de Droysen, Hegel, a formação (Bildung) opõe-se tanto à "subsistência física" quanto ao "caráter singular" do ser humano. ${ }^{34}$ Formação é, para ele, aquele processo intelectual que possibilita a autoelevação do indivíduo ao geral por meio do sacrifício do particular. ${ }^{35}$ Droysen coloca essa ideia geral de formação para funcionar em conjunto com a ideia de história e com a prática da historiografia. Ele afirma que

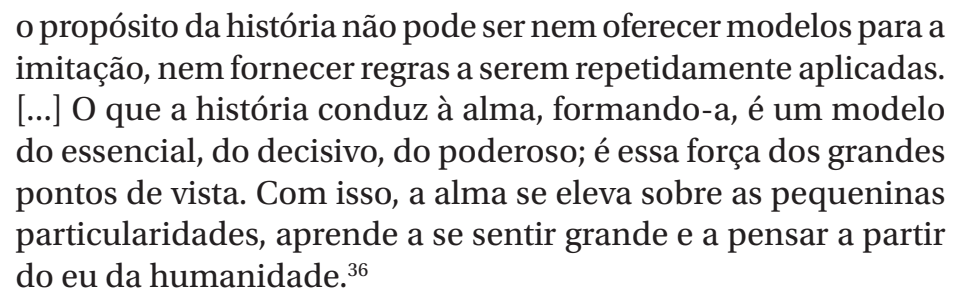

Traduzindo em linhas bem gerais: para Droysen, o pensamento histórico é um dos meios da Bildung, da autoformação resultante da internalização subjetiva do estoque cultural acumulado no decurso da história da humanidade.

É de se ressaltar que, nos quadros do humanismo universalista de Droysen, o pensamento histórico não é apenas o fundamento do método científico a partir do qual se produz conhecimento acerca do passado humano. Segundo ele, embora o conhecimento histórico seja um óbvio produto do pensamento

\footnotetext{
33Johann Gustav Droysen, Historik. Vol. 1: Rekonstruktion der ersten vollständigen Fassung der Vorlesungen (1857); Grundriß der Historik in der ersten handschriftlichen (1857-1858) und in der letzten gedruckten Fassung (1882), editado por Peter Leyh, Stuttgart, Frommann-Holzboog, 1977, p. 106.

${ }^{34}$ Georg Friedrich Hegel, Nürnberger und Heidelberger Schriften: 1808-1817, Frankfurt am Main, Suhrkamp, 1986, p. 258.

${ }^{35}$ Rudolf Vierhaus, "Bildung;, In: Otto Brunner et al. (orgs.), Geschichtliche Grundbegriffe: historisches lexikon zur politisch-sozialen Sprache in Deutschland, vol. 1. Stuttgart, Klett-Cotta, 1979, p. 508-551 (esp. p. 535); Gadamer, Verdade e método. Vol. 1: traços fundamentais de uma hermenêutica filosófica, Petrópolis, Vozes, 2008, p. 47-51.

36Johann Gustav Droysen, op. cit., p. 251-252 (tradução do autor).
} 
histórico, este último, inversa e dialeticamente, também representa a meta final do conhecimento. Isso implica que os historiadores tenham por tarefa não só o pensar historicamente, mas também transmitir socialmente a maneira de pensar que é característica do seu método geral de trabalho. A transmissão e a difusão do pensamento histórico tornam-se, deste modo, a grande função educadora da historiografia. Droysen aborda o tema da transmissão e aquisição da capacidade de pensar historicamente a partir de um conceito paralelo ao de "pensamento histórico", tomado de empréstimo junto a Wilhelm von Humboldt: o de "senso de realidade". ${ }^{37} \mathrm{Na}$ definição idealista de Humboldt, "senso de realidade" figura como a competência subjetiva elementar da percepção histórica. É aquilo que permite ao historiador captar cognitivamente a dinâmica profunda da realidade histórica e enxergar as forças que atuam por detrás da superfície dos eventos para lhes dar forma e direção. Segundo Humboldt, os historiadores deveriam não apenas aplicar tal competência para representar os acontecimentos passados, mas também buscar "despertar e dar vida" ao senso de realidade dos seus destinatários. ${ }^{38}$

Como se vê, na definição metodológica de Humboldt, já estão embutidos caracteres decididamente didáticos, que Droysen posteriormente acentuaria e sistematizaria. Para este, o senso de realidade estaria consolidado nos estudantes (escolares ou não) de história, uma vez que eles estivessem em condição de aplicar à interpretação de seu próprio presente a forma de pensamento aprendida junto às histórias. No modelo didático não exemplar projetado por Droysen, as histórias favorecem, antes de tudo, o desenvolvimento de uma capacidade que permite ao sujeito humano perceber a historicidade do seu próprio presente; que lhe faculta, portanto, dimensionar as condições reais que estruturam o seu próprio mundo. A isso se liga a expectativa de que $o$ desenvolvimento da capacidade de pensar historicamente também reforçaria a capacidade subjetiva de tomar decisões práticas e de agir de modo razoável. Na base dessa relação, encontra-se uma multifacetada "razão histórica", ou seja, um tipo de racionalidade ao mesmo tempo cognitiva e prática que os historiadores não apenas exercitam, mas também seriam capazes de transmitir à sua audiência. Tal vínculo entre conhecimento e práxis, selado por uma forma de racionalidade comum a ambos, seria mais tarde colocado em primeiro plano por Jörn Rüsen - não por acaso, o teórico da história em atuação nos dias de hoje que mais fortemente se inspirou no pensamento de Droysen. ${ }^{39}$

A vizinhança entre os conceitos de "pensamento histórico", "senso de realidade" e "Bildung" é uma das provas decisivas da distância entre a didática da história proposta por Droysen e aquela que se encontra embutida

\footnotetext{
${ }^{37}$ Johann Gustav Droysen, Historik. Vol. 1: Rekonstruktion der ersten vollständigen Fassung der Vorlesungen (1857); Grundriß der Historik in der ersten handschriftlichen (1857-1858) und in der letzten gedruckten Fassung (1882), editado por Peter Leyh, Stuttgart, Frommann-Holzboog, 1977, p. 5; 40.

${ }^{38}$ Wilhelm von Humboldt, "Sobre a tarefa do historiador", In: Estevão de Rezende Martins (org.), A história pensada. Teoria e método na historiografia europeia do século XIX, São Paulo, Contexto, 2010, p. 86 (tradução ligeiramente modificada).

${ }^{39}$ Jörn Rüsen, Razão histórica. Teoria da história: os fundamentos da ciência histórica, Brasília, Editora da UnB, 2001, p. 11-15.
} 
na "teoria exemplar da história". Na sua exposição referente à "narrativa didática", Droysen expressa uma consciência muito clara de tal distanciamento. "Era", afirma ele, "o fundamento da história falsamente chamada pragmática o de que, da história, se deveria aprender como agir, no futuro, em casos similares". ${ }^{40}$ A expressão "história falsamente chamada pragmática" remete aqui, é claro, ao tipo de historiografia que corresponde à teoria exemplar da história. Na citação mencionada, Droysen nega plausibilidade às histórias concebidas de acordo com o modelo pragmático-exemplar. A forma de pragmatismo histórico que ele aceitava como válida não era aquela que conduz à elaboração de catálogos supratemporais de ações pretéritas imitáveis ou evitáveis. Pelo contrário, para ele, todo pragmatismo histórico plausível somente podia surgir do estímulo fornecido pelas histórias à autoformação dos seus leitores.

Droysen clarifica a diferença entre os modos exemplar e formativo de aprendizagem histórica, remetendo a um campo historiográfico de suma importância à sua época, a história militar. Para os oficiais de um exército, aponta ele, seria mais do que interessante estudar como os grandes generais do passado se comportaram em determinados casos. Mas o que um oficial do presente pode aprender com a leitura de histórias de guerra não são regras de conduta cuja observância garantiria o sucesso nos campos de batalha. Das histórias, ele aprenderia, sobretudo, a ganhar "uma compreensão para o que foi vivido pelo espírito". Lendo-as, ele faria, assim, uma espécie de "exercício mental". ${ }^{41}$ Para Droysen, a Bildung, a formação histórica, corresponde exatamente a esse tipo de "exercício mental", ilustrado pelo caso da história militar. Deve-se notar que o argumento aqui não concerne somente à história militar em particular, mas à história no geral. Assim como os militares leitores, também os adeptos de outras profissões não encontrariam nas histórias indicações concretas acerca de como deveriam viver suas vidas, ou de que decisões deveriam tomar. De acordo com Droysen, o conhecimento que se pode extrair das histórias é, com efeito, prático, mas a sua praticidade não é nem exemplar, nem imediata. Antes, pelo contrário, a leitura de histórias representa, segundo ele, a ocasião de um "exercício mental" o qual conduz ao aprendizado de uma capacidade reflexiva: a de pensar historicamente.

\section{0 atual e 0 inatual}

Nunca é demais lembrar que a modalidade de educação histórica teorizada por Droysen é o produto de um cenário político e cultural bastante distinto do nosso. Trata-se de um modelo teórico que Droysen combinou a uma visão concreta de política e de sociedade, cujos contornos eram, mesmo no contexto

\footnotetext{
40 Johann Gustav Droysen, Historik. Vol. 1: Rekonstruktion der ersten vollständigen Fassung der Vorlesungen (1857); Grundriß der Historik in der ersten handschriftlichen (1857-1858) und in der letzten gedruckten Fassung (1882), editado por Peter Leyh, Stuttgart, Frommann-Holzboog, 1977, p. 250.

41/dem, Ibidem, p. 250-251.
} 
da sua própria época, abertamente antidemocráticos e não inteiramente liberais. ${ }^{42}$ Especialmente depois que fracassa a tentativa de unificação da Alemanha articulada pela assembleia constituinte estabelecida com a Revolução de 1848, os textos políticos de Droysen passam a revelar uma redução do interesse por temas liberais, como os dos direitos fundamentais e das liberdades civis, além de uma crescente concentração em problemas da Realpolitik. Na teoria política que ele desenvolveu em preleções proferidas em 1850, lê-se, por exemplo, que "a essência do estado é constituir-se em poder, poder para dentro e poder para fora". ${ }^{43}$ Mais tarde, na sua argumentação em favor do estado forte, Droysen chega até mesmo ao ponto de afirmar que as ciências históricas deveriam ser situadas no "âmbito da preparação espiritual para a guerra". ${ }^{4}$

Também não é difícil perceber que Droysen tomava o pensamento histórico e o senso de realidade como competências restritas a uma mera fração da sociedade. De fato, como quase todos os teóricos da história no século XIX, ele pressupõe que as transformações verdadeiramente históricas dependem diretamente apenas de alguns indivíduos, que denominava "artífices da história". Era exatamente nestes que Droysen queria ver fomentada a capacidade para pensar historicamente. ${ }^{45}$ A filosofia social aqui implícita admite que, na prática, a capacidade potencial para a tomada de consciência histórica se restringe a príncipes, estadistas, altos funcionários da burocracia, comandantes militares e, claro, intelectuais — todos do sexo masculino. Além disso, a preocupação primária de Droysen era a de promover o pensamento histórico de estadistas, burocratas, militares e intelectuais alemães e não necessariamente de outras nacionalidades. E aqui ainda é preciso lembrar: ele acreditava que elites políticas aptas para pensar historicamente chegariam automática e necessariamente à conclusão - que ele obviamente endossava - de que a Prússia estava investida da grande missão histórica de promover a unificação dos estados alemães e, com isso, garantir a continuidade do próprio processo histórico como um todo. ${ }^{46}$

Portanto, na teoria, Droysen definiu o pensamento histórico de uma maneira aberta e universalista, mas tal universalismo às vezes se dissipou na prática, uma vez que ele, dentro das circunstâncias concretas de pensamento e atuação sob as quais vivia, muitas vezes fez opções políticas e historiográficas de caráter particularista. ${ }^{47}$

\footnotetext{
${ }^{42}$ Robert Henry Handy, J.G. Droysen: the historian and German politics in the nineteenth century, Tese de doutorado, Georgetown University, Washington, D.C., 1966, p. 87-99.

${ }^{43}$ Johann Gustav Droysen, Historik. Vol. 2: Texte im Umkreis der Historik (1826-1882), editado por Horst Walter Blanke, Stuttgart, Frommann-Holzboog, 2007, p. 322.

${ }^{44}$ /dem, Ibidem, p. 455.

45/dem, Historik. Vol. 1: Rekonstruktion der ersten vollständigen Fassung der Vorlesungen (1857); Grundriß der Historik in der ersten handschriftlichen (1857-1858) und in der letzten gedruckten Fassung (1882), editado por Peter Leyh, Stuttgart, Frommann-Holzboog, 1977, p. 386-388.

${ }^{46} / d e m$, Politische Schriften, editado por Felix Gilbert, München, R. Oldenbourg, 1933, p. 228-229.

${ }^{47}$ Eu próprio tentei explicar essas dissonâncias entre teoria e prática no pensamento de Droysen. Ver Arthur Alfaix Assis, What is history for?, New York, Berghahn Books, 2014, esp. p. 146-170.
} 
Esses descompassos entre a didática do pensamento histórico desenvolvida por Droysen e as suas efetivas aplicações práticas sinalizam para a complexa problemática da atualidade e legado das ideias do autor. No essencial, contudo, eu defendo que a resposta de Droysen à questão "por que?", isto é, por que pesquisar, escrever, ensinar e aprender história, ainda se sustenta. ${ }^{48}$ Em primeiro lugar, pela simples razão de que a capacidade de pensar historicamente, que Droysen conecta à aprendizagem histórica, não se liga a nenhum cânone fixo de conteúdos. O conteúdo do nosso pensamento histórico, os objetos sobre os quais pode atuar a nossa capacidade de historicizar, não necessariamente precisam ser os mesmos privilegiados por Droysen. Na verdade, o pensamento histórico tal como teorizado por Droysen pode ser tomado como uma competência puramente formal, aplicável a qualquer conteúdo de experiência e conjugável com diversos conjuntos de normas e valores. Assim, a preferência de Droysen por enquadrar temas políticos desde um ponto de vista germanocêntrico, pró-Prússia, masculino, burguês-ilustrado e antipopular não implica necessariamente que nós tenhamos de aderir a essas mesmas escolhas e perspectivas. Nada impede, por exemplo, que se pense historicamente sobre fenômenos culturais desde uma perspectiva feminista ou marxista; ou sobre temas econômicos desde um ponto de vista conservador, e assim por diante.

\section{Defendo que a resposta de Droysen à questão "por que?", isto é, por que pesquisar, escrever, ensinar e aprender história, ainda se sustenta}

Em segundo lugar, é preciso lembrar que, na obra teórica de Droysen, vemos já claramente definido um horizonte de ideias básicas dentro do qual ainda hoje se move parte significativa da reflexão sobre a aprendizagem histórica. Bastante consensual entre os especialistas em educação histórica é a opinião de que o objetivo do ensino escolar de história e da aprendizagem histórica em geral não deve ser o da mera transmissão/aquisição de informações fatuais. Já há algumas décadas, esse consenso quanto à insuficiência de uma concepção puramente fatualista do ensino de história tem estimulado a difusão de definições positivas com respeito aos objetivos da aprendizagem histórica.

\footnotetext{
${ }^{48}$ Para um bom balanço geral da atualidade da obra de Droysen (além de indicações sobre a história da recepção desta), ver Pedro Spinola Pereira Caldas, "A atualidade de Johann Gustav Droysen: uma pequena história de seu esquecimento e de suas interpretações”, Locus, vol. 12, n. 1, 2006, p. 95-111.
} 
Dois conceitos que resumem boa parte dessas definições são amplamente coincidentes: "pensamento histórico" e "consciência histórica". ${ }^{49}$

Mas também é importante ter em mente: a linha que vai da didática da história de Droysen até nós não é direta e as remissões aos seus argumentos nos debates contemporâneos são, antes de tudo, escassas. Além disso, a generalidade de tais conceitos didáticos faz com que, muitas vezes, os seus usos e significados concretos variem bastante. $\mathrm{O}$ consenso genérico quanto à necessidade de se estimular o desenvolvimento da consciência histórica às vezes sobrepõe-se à cacofonia dos entendimentos colidentes sobre o que concretamente seria tal consciência, mas com certeza não a abafa. Em todo caso, a história das diferentes mediações que conduziram da justificativa de Droysen para o estudo da história às reflexões didáticas atuais está ainda para ser contada.

Em terceiro e último lugar, a atualidade das definições didáticas de Droysen remete à problemática do legado do historicismo em geral. A definição da função da história desenvolvida por Droysen é parte importante da "revolução espiritual" promovida pela afirmação do historicismo na Alemanha entre os séculos XVIII e XIX. ${ }^{50}$ Estou tomando "historicismo" aqui num sentido amplo, como o equivalente de uma maneira de explicar o mundo estruturada em torno da crença de que certos fenômenos podem ser bem compreendidos por meio da sua historicização. ${ }^{51}$ Pouco se pensa nisso, mas "historicização" possui dois significados simultâneos. Aponta tanto para um tipo de apreensão das coisas centrado naquilo que as individualiza quanto para a percepção de uma dada ordem de coisas enquanto resultado (provisório) de um processo mais abrangente iniciado num momento anterior do tempo.$^{52} \mathrm{O}$ historicismo é, portanto, uma maneira de olhar para o mundo que enfatiza a individualidade e a

\footnotetext{
${ }^{49}$ Ver, por exemplo, Bodo von Borries, Historisch Denken Lernen. Welterschließung statt Epochenüberblick. Geschichte als Unterrichtsfach und Bildungsaufgabe, Opladen, Barbara Budrich, 2008; Ignacio Muñoz Delaunoy, “La historia y sus funciones”, In: Ignacio Muñoz Delaunoy; Luis Osandón Millavil (orgs.), La didáctica de la historia y la formación de ciudadanos en el mundo actual, Santiago, Ediciones de la Dirección de Bibliotecas Archivos y Museos, 2013, p. 25-43 (esp. p. 39-40); Karl-Ernst Jeismann, "Geschichtsbewußtsein - Theorie", In: Klaus Bergmann et al. (orgs.), Handbuch der Geschichtsdidaktik, Seelze-Velber, Kallmeyer, 1997, p. 42-45; Hans-Jürgen Pandel, Geschichtsunterricht nach PISA. Kompetenzen, Bildungsstandards und Kerncurricula, Schwalbach am Taunus, Wochenschau, 2007; Pieter van Veuren, "Does it make sense to teach history through thinking skills?", Koers, vol. 60, n. 1, 1995, p. 29-39; Sam Wineburg, Historical thinking and other unnatural acts. Charting the future of teaching the past, Philadelphia, Temple University Press, 2001. 0 mesmo vale também para o debate brasileiro sobre o tema. Ver, por exemplo, Oldimar Cardoso, "Para uma definição de didática da História”, Revista Brasileira de História, vol. 28, n. 55, 2008, p. 153-170; Luis Fernando Cerri, "Didática da História: uma leitura teórica sobre a História na prática”, Revista de História Regional, vol. 15, n. 2, 2010, p. 264-278; Estevão de Rezende Martins, "História: consciência, pensamento, cultura, ensino", Educar em revista, n. 42, 2011, p. 43-58 (esp. p. 52-58); Rafael Saddi, “O parafuso da didática da História”, Acta Scientiarum Education, vol. 34, n. 2, 2012, p. 211-220.

${ }^{50}$ Friedrich Meinecke, "A formação do historicismo - considerações preliminares", In: Jurandir Malerba (org.), Lições de História. Da história científica à crítica da razão metódica no limiar do século XX. Porto Alegre, EdiPUC-RS, 2013, p. 263-272 (esp. p. 263).

${ }^{51}$ Não se trata, destarte, de "historicismo" na acepção popularizada por Karl Popper. Sobre as diferentes acepções do termo, ver Friedrich Jaeger, "Historismus", In: Friedrich Jaeger (org.), Enzyklopädie der Neuzeit. Vol. 5, org., Stuttgart, J.B. Metzler, 2007, p. 532-539. Na tradução de "Historismus" para o português, optei por "historicismo" em vez de "historismo", por ser a primeira opção a mais próxima da terminologia mais comumente utilizada entre os autores não alemães que tratam da matéria.

${ }^{52}$ Maurice Mandelbaum, History, man, \& reason: a study in nineteenth-century thought, Baltimore, The Johns Hopkins Press, 1971, p. 41-43.
} 
transitoriedade das coisas. ${ }^{53}$ A sua premissa fundamental é a de que os fenômenos humanos apenas são bem compreendidos quando se coloca o que é ou foi sob a perspectiva do seu próprio devir. ${ }^{54}$

Contudo, desde o final do século XIX, a visão de mundo historicista foi repetidas vezes colocada em xeque. A intensificação de processos, tais como a industrialização da Alemanha, a democratização, a secularização e o advento da Primeira Guerra Mundial, teria retirado credibilidade do tipo de fundamentação de valores e normas favorecido na era clássica do historicismo. ${ }^{55}$ Além disso, a pretensão nutrida pelo historicismo clássico de ser a única forma legítima de abordagem dos assuntos humanos fragilizou-se com a consolidação de abordagens a- ou anti-históricas desenvolvidas no âmbito da economia, da linguística, da psicologia, da sociologia, da antropologia e de outras ciências. ${ }^{56}$ O descrédito do historicismo atingiu um patamar particularmente elevado quando, nos anos 1960 e 1970, muitos historiadores que pretendiam renovar a cena historiográfica alemã, pelo aporte de conceitos e métodos das ciências sociais, definiram o seu projeto como uma tentativa de "superação do historicismo" ${ }^{57}$ Para piorar, o desconforto inaugurado após a Segunda Guerra Mundial com categorias desenvolvimentistas, como progresso ou evolução social, bem como a posterior crítica pós-moderna das metanarrativas, prepararia terreno para que se chegasse até mesmo a falar na dispensabilidade do conceito de história e da própria tradição historiográfica. ${ }^{58}$

Tudo isso colide com a noção de pensamento histórico de Droysen e com a didática histórica a ela vinculada. Mas não creio que isso seja motivo suficiente para atirar ao limbo o legado de Droysen e muito menos do historicismo e da tradição historiográfica moderna. A maior parte da literatura sobre a "crise do historicismo" dramatiza em excesso o impacto de tal crise, que parece ter sido realmente traumática apenas nos quadros da tradição da filologia bíblica e da reflexão neokantiana sobre a fundamentação de valores universais. ${ }^{59}$ Noutras

\footnotetext{
53Beiser, The German historicist tradition, Oxford, Oxford University Press, 2011, p. 2-5.

${ }^{54} J$ Johann Gustav Droysen, Historik. Vol. 1: Rekonstruktion der ersten vollständigen Fassung der Vorlesungen (1857); Grundriß der Historik in der ersten handschriftlichen (1857-1858) und in der letzten gedruckten Fassung (1882), editado por Peter Leyh, Stuttgart, Frommann-Holzboog, 1977, p. 162; Johann Gustav Droysen, Historik. Vol. 2: Texte im Umkreis der Historik (1826-1882), editado por Horst Walter Blanke, Stuttgart, FrommannHolzboog, 2007, p. 508.

${ }^{55}$ Herman Paul, "A collapse of trust: reconceptualizing the crisis of historicism", Journal of the Philosophy of History, vol. 2, n. 1, 2008, p. 63-82 (esp. p. 73-74).

${ }^{56}$ Reinhart Koselleck, “Wozu noch Historie?”, In: Wolfgang Hardtwig (org.), Über das Studium der Geschichte, München, DTV, p. 347-365 (esp. p. 348-351).

${ }^{57}$ René Gertz, "O historicismo e a moderna história social alemã”, In: Flávia Varella et al. (orgs.), A dinâmica do historicismo. Revisitando a historiografia moderna, Belo Horizonte, Argumentum, 2008, p. 149-168 (esp. p. 151 et seq.); Thomas Welskopp, "Limites e perspectivas da ciência social histórica”, História da Historiografia, n. 6 , 2011, p. 14-41 (esp. p. 19).

${ }^{58}$ Para uma reavaliação crítica de parte de tais diagnósticos gerais, ver Pietro Rossi, Naufrágio sem espectador: a idéia de progresso, São Paulo, Editora da Unesp, 2000, p. 122-132. Para uma crítica radical da historiografia, que procura afirmar com todas as letras ser hoje dispensável tanto o conceito de história quanto o conhecimento produzido pelos historiadores acadêmicos, ver Keith Jenkins, Why history? Ethics and postmodernity, London, Routledge, 1999, p. 1.

${ }^{59}$ Allan Megill, “Why was there a crisis of historicism?”, History and Theory, vol. 36, n. 3, 1997, p. 416-429 (esp. p. 419-422); Frank Ankersmit, Meaning, truth, and reference in historical representation, Ithaca, Cornell University Press, 2012, p. 5-7.
} 
searas, o impacto da historicização parece ter sido menos duro, neutro ou até mesmo positivo. Pense-se somente numa abordagem interdisciplinar muito estimada hoje em dia, a história dos conceitos, abordagem essa que, em larga medida, é fruto do processo de historicização da filosofia iniciado na Alemanha do século XIX.60

De qualquer modo, as muitas "crises" do historicismo não parecem ter sido fortes o suficiente para invalidar a posição segundo a qual uma maneira privilegiada de entender o mundo humano do passado e do presente é enfocar conjuntos de transformações que produziram certas ordens de coisas singularizáveis. Também não parecem ter conduzido a uma convicção irrefutável de que haveria algo de errado em tentar enriquecer a compreensão do presente com a compreensão do passado e vice-versa. Afinal de contas, quantos historiadores reais parecem estar seriamente dispostos a abrir mão dos procedimentos reunidos no termo "historicização"? Como bem observou Sérgio da Mata, "uma história radicalmente anti-historicista deixa de ser história". ${ }^{61}$

Como se vê, eu particularmente defendo que o historicismo e a sua didática da história continuam atuais. O historicismo compôs, entre outras coisas, uma descrição geral do que está em jogo na prática historiográfica, a qual, na minha opinião, é até hoje uma das melhores ofertas disponíveis no mercado da teoria da história. Agora, trata-se de uma descrição composta já há muitas décadas, com o auxílio de um vocabulário idealista que há muito deixou de ser satisfatório. ${ }^{62}$ É difícil associar o trabalho dos historiadores de hoje à investigação de "forças éticas", ou do "devir das ideias", à tarefa da "teodiceia", ou a conceitos como "espírito", "eu da humanidade", "espírito nacional”, "artífices da história”, para ficar apenas com alguns exemplos extraídos da obra do próprio Droysen. E mesmo o termo Bildung, com as suas infinitas dificuldades de tradução e as suas intrincadas conotações místicas, religiosas, psicológicas e filosóficas, talvez não seja a melhor aposta da reflexão internacional sobre a aprendizagem histórica. Nada disso interfere, porém, nas premissas centrais do historicismo. Estas podem e devem, como Frank Ankersmit sugeriu recentemente, ser traduzidas num vocabulário mais contemporâneo. ${ }^{63}$ Uma tal tradução que não só interpreta, mas também busca atualizar a didática historicista de Droysen, corresponde a boa parte do que acabei de tentar fazer.

\footnotetext{
${ }^{60}$ Gunter Scholtz, "Begriffsgeschichte als historische Philosophie und philosophische Historie", In: Hans Joas; Peter Vogt, Begriffene Geschichte. Beiträge zum Werk Reinhart Kosellecks, Frankfurt am Main, Suhrkamp, 2011, p. 264-287.

${ }^{61}$ Sérgio da Mata, "Elogio do historicismo”, In: Flávia Varella et al. (orgs.), A dinâmica do historicismo. Revisitando a historiografia moderna, Belo Horizonte, Argumentum, 2008, p. 49-62 (esp. p. 55).

${ }^{62}$ Ankersmit, Meaning, truth, and reference in historical representation, Ithaca, Cornell University Press, 2012, p. 256. 63/dem, Ibidem, p. 1-2.
} 